\section{Factors Influencing Willingness to Pay for Multiple Micronutrient Powder (Virutubishi) Supplements for Young Children in Arusha, Tanzania}

\begin{abstract}
Background: Multiple micronutrient powders have shown a positive effect on anaemia prevention in children 6-59 months. For the purposes of uptake and sustainability, we explored "willingness to pay" for these health products at the household level for potential of co-investment in multiple micronutrient powders.

Methods: During the intervention (six months), household surveys were conducted once with mothers of children 6-59 months in the Arusha District regarding willingness to pay for the multiple micronutrient powders.

Results: Results from the survey show that about $66 \%$ of the target mothers are willing to pay for multiple micronutrient powders required for feeding of children at $0.068 \$$ per sachet. Willingness to pay was associated with higher paternal education, higher maternal age, and families which do not keep animals.

Conclusion: The results findings help to know the market situation of nutritional products. This information is useful for health policy planners in assessing economic viability and sustainability of the distribution of multiple micronutrient powders to consumers to avert micronutrient deficiencies and their effects on young children.
\end{abstract}

Keywords: Multiple micronutrient powder; Willingness to pay; Childhood anaemia; Tanzania
Kejo D ${ }^{1,3 *}$, Martin $\mathrm{H}^{1}$, Mosha TCE ${ }^{2}$, Petrucka $\mathrm{P}^{3}$ and Kimanya $\mathrm{ME}^{4}$

\section{Department of Food Science and} Nutrition, Nelson Mandela African Institution of Science and Technology, Arusha, Tanzania

2 Department of food Technology, Sokoine University of Agriculture, Nutrition and Consumer Sciences, Morogoro, Tanzania

3 College of Nursing, Saskatoon, University of Saskatchewan, Canada; Adjunct NMAIST, Tanzania

4 Tanzania Agriculture Research Institute (TARI) Tengeru, Arusha, Tanzania

\section{*Corresponding author: Dyness Kejo \\ kejod@nm-aist.ac.tz}

Department of Food Science and Nutrition, Nelson Mandela African Institution of Science and Technology, Arusha, Tanzania.

Tel: +255767596284

Received: September 26, 2018; Accepted: November 06, 2018; Published: November 21, 2018

\section{Introduction}

The most common cause of anaemia worldwide is iron deficiency, resulting from prolonged negative iron balance, caused by inadequate dietary iron intake or absorption [1]. According to the WHO (2001), the relative proportion of anaemia due to iron deficiency increases as the prevalence of anaemia increases and iron deficiency will be 2.5 times that of anaemia [2]. In any population if prevalence rate exceeds $40 \%$, the condition is considered a severe public health risk [3]. Anaemia is a major global public health problem affecting about $50 \%$ of children under-five years (U5s) [3]. In Tanzania, anaemia is prevalent among all age groups but children between 6-59 months are highly (58\%) affected [4]. This trend is attributed to consumption of lower than the recommended daily iron requirement from complementary foods (CFs), as most of the consumed iron is plant based which, as compared to animal source iron is not as
Citation: Kejo D, Martin H, Mosha TCE, Petrucka P, Kimanya ME (2018) Factors Influencing Willingness to Pay for Multiple Micronutrient Powder (Virutubishi) Supplements for Young Children in Arusha, Tanzania. J Health Med Econ Vol.5 No.1:8 readily absorbed in the body. Further, there is limited access to food in most households a condition that leads to most children experiencing iron deficiency [5]. The alarmingly high prevalence of anaemia among U5s, coupled and associated with adverse health development and economic consequences highlights the need for intensified actions to address this ongoing public health problem.

Home fortification with MNP is a cost-effective intervention, which was developed to tackle the problem of childhood anaemia by delivering iron and a blend of other essential vitamins and minerals that can easily be mixed into available CFs 
before serving [6]. The Home Fortification Technical Advisory Group (HF-TAG) and WHO made a recommendation on MNP availability to target groups including the frequency and duration of supplementation [7]. They recommend when; dietary diversity is low, poor bio-availability of micronutrient in plant-based foods (due to inhibitors in the diet) and low nutrient content of complementary foods. Several trials suggest that iron-containing MNP administered daily [8-11], weekly [12] or according to flexible regimens [13] is effective to reduce anaemia and increase haemoglobin level for children.

For sustainability of nutritional supplementation such as MNP, the government has introduced a private market approach to sell the MNPs to target populations at a controlled cost of about 0.068 US\$ per sachet. Given the diversity of families in terms of education level, maternal age and food security it remains unclear whether parents will be willing or able to pay for the micronutrients. The objective of this study was to determine the socio-economic factors affecting willingness to pay for the MNPs and amount of money families are willing to pay for the service.

\section{Methodology}

\section{Study area}

The study was conducted in Arusha District, which surrounds the Arusha City in Tanzania. The District is primarily rural with socioeconomic patterns that are similar to those of most districts in Tanzania. The districts is characterized with cultural diversity and reports childhood anaemia prevalence similar or above national levels [4].

\section{Sample size and sampling technique}

Within the Arusha District, there are twenty wards each having at least one reproductive child health $(\mathrm{RCH})$ clinic for mothers and children. Of these, three wards - Oldonyosambu, Oturumeti and Seliani - were randomly selected for the study. At each site, the researcher, with the help of village health workers identified households with children between 6-59 months of age. The sample size was determined using the statistical power analysis formula $n=z^{2} p(1-p) / d^{2}$ [14] for anaemia assessment, where $n=$ sample size $p=$ prevalence of anaemia (60\%) (TDHS, 2010), $z=z-$ value at $95 \%$ confidence $(=1.96), d=$ level of significance $(=5 \%)$, with an anticipated attrition of $18 \%$ to follow-up yielded a total of 436 mother-child pairs.

Inclusion criteria were: the family had to reside to the selected ward; the child must 6-59 months of age, haemoglobin $(\mathrm{Hb})$ levels from 7.0-9.9 g/dL and children who started complementary foods. Exclusion criteria were $\mathrm{Hb}$ concentrations $\leq 6.99 \mathrm{~g} / \mathrm{dL}$ or $\geq 10.0 \mathrm{~g} / \mathrm{dL}$ ), child who does not consume solid foods, chronic conditions such as type 1 diabetes mellitus, some inborn errors of metabolism, HIV infection or known hemoglobinopathies. About 369 children were eligible to participate in the study and those who agreed gave written consent. However, 58 mothers did not gave consent to participate in the study. Thus 310 mothers-child pairs-were recruited and participated in the study.

\section{Data collection}

A structured pretested questionnaire was used as part of a face to face data collection. During the baseline survey socioeconomic and demographic data, such as education level, age, land ownership, household size and income were collected. During the intervention (six months) the MNP sachets were provided for free to the participants. Therefore, the parents were once asked if they would be willing to pay/buy the sachets at a price of TZS 150 (USD 0.068).

\section{Assessment of willing to pay micronutrient powders}

The MNP for which the WTP was explored to mothers-children pairs involved in the intervention was manufactured by Manisha Pharmo Plast Pvt. Ltd. (Umbergaon-396171. Gujarat India.). The components and composition of the multi-micronutrient formula are based on the recommendations by UNICEF/WHO/ WFP. The MNP contains 15 vitamins and minerals based on the Recommended Nutrient Intake (RNI) for children [7]. The nutrient content for $1 \mathrm{~g}$ of MMP includes vitamin A (RE $400 \mu \mathrm{g})$, vitamin D3 $(5 \mu \mathrm{g})$, vitamin E (TE $5 \mathrm{mg})$, vitamin B1, B2, B6 each (0.5 mg), folic acid (15 mg), niacin (6 mg), vitamin B12 (0.9 $\mu \mathrm{g})$, vitamin C (30 mg), iron (10 mg), zinc (4.1 mg), selenium (17 $\mu \mathrm{g})$, copper $(0.56 \mathrm{mg})$, and iodine $(90 \mu \mathrm{g})$. The MNP has to be supplied in a single-dose sachet ( 1 dose $=1$ sachet) and one pack contained $30 \times 1$ g sachets.

\section{Data management and analysis}

Data management and analysis were accomplished using SPSS version 21 and Chi-square test for a categorical variable. A logistic regression model was performed to estimate the determinant of being willing to pay for the MNP at the price of TZS150 (USD 0.068 ) based on socioeconomic and demographic characteristics.

\section{Results}

The summary of respondent's demographic characteristics with respect to WTP for MNP is reported in Table 1 . There is a significant $(P<0.01)$ association of willing to pay for MNPs and mothers age.

\section{Determinant of willing to pay for MNPs}

Table 2 presents estimated coefficient of logistic regression that examines the effect of WTP for micronutrients. In univariate analysis, mother's age, a family who do not keep animals and parents with low income (<1.14 US\$) were found to be determinants of WTP. These results were confirmed in multivariate analysis with mothers aged above 35 years (OR: 4.9 (1.7-14.2) being more likely to pay for MNP compared to younger mothers. Fathers with primary education (OR: 3.1 (1.2-7.9) and parents who do not keep animals (OR: 2.5 (1.4-4.5) were more likely willing to pay for MNP.

\section{Discussion}

Little is known about WTP for nutritional supplements like MNP 
Table 1 Socio-economic and demographic characteristics on consumer willingness to pay for MNP.

\begin{tabular}{|c|c|c|c|}
\hline & $\mathbf{N}$ & $\mathbf{N}(\%)$ & P-value \\
\hline \multicolumn{4}{|l|}{ Child's gender } \\
\hline Female & 130 & $89(43.8)$ & 0.48 \\
\hline Male & 180 & $114(56.2)$ & \\
\hline \multicolumn{4}{|l|}{ Age (months) } \\
\hline 43410 & 86 & $52(25.6)$ & 0.56 \\
\hline 45261 & 114 & 77 (37.9) & \\
\hline $24-35$ & 70 & $44(21.7)$ & \\
\hline $36-59$ & 40 & $30(14.8)$ & \\
\hline \multicolumn{4}{|l|}{ Mother's age(years) } \\
\hline $15-24$ & 143 & $92(45.3)$ & \\
\hline $25-34$ & 146 & $105(51.7)$ & $0.002 *$ \\
\hline $35-49$ & 21 & $6(3.0)$ & \\
\hline \multicolumn{4}{|l|}{ Father's education } \\
\hline No formal education & 33 & $25(12.3)$ & 0.24 \\
\hline Primary & 241 & $152(74.9)$ & \\
\hline Secondary & 36 & $26(12.8)$ & \\
\hline \multicolumn{4}{|l|}{ Mother's education } \\
\hline No formal education & 54 & $33(16.3)$ & 0.09 \\
\hline Primary only & 195 & $124(61.1)$ & \\
\hline Secondary & 61 & $46(22.7)$ & \\
\hline \multicolumn{4}{|l|}{ Livestock keeping } \\
\hline Yes & 207 & $122(60.1)$ & $0.00 *$ \\
\hline No & 103 & 81 (39.9) & \\
\hline \multicolumn{4}{|l|}{ Source of food } \\
\hline Own production & 85 & $52(25.6)$ & 0.18 \\
\hline Buying & 225 & $151(74.4)$ & \\
\hline \multicolumn{4}{|l|}{ Occupation } \\
\hline Employed & 31 & $22(10.8)$ & 0.4 \\
\hline Farmers & 175 & $118(58.1)$ & \\
\hline Pastoralist & 52 & $26(12.8)$ & \\
\hline Casual labour & 43 & $31(15.3)$ & \\
\hline Business & 9 & $6(3.0)$ & \\
\hline \multicolumn{4}{|l|}{ Income (US\$ per day) } \\
\hline$>1.14$ & 45 & $35(17.2)$ & 0.17 \\
\hline$<1.14$ & 265 & $168(82.8)$ & \\
\hline
\end{tabular}

in Tanzania and East Africa. Willingness to pay is the maximum amount an individual is willing to spend to procure a product or service [15] and the price of the transaction will be at a point somewhere between a buyer's WTP and a seller's willingness to accept. Studies in Tanzania report on WTP for safety inspected tomatoes, organic products, and health services $[16,17]$.

The results from this study provide insight into society's use of their financial assets for nutritional products like MNP as part of their strategies for addressing their children's health. These results also indicate that micronutrient supplementation is highly valued by parents. Results shows that more than half of the mothers (65.5\%) involved in the intervention were WTP for MNP at the given price of 150 Tanzanian Shillings (USD 0.068) after observing effectiveness in improving children's health. These findings align with other studies in developing countries $[18,19]$, where women are the main/primary caretakers of their households. They plan
Table 2 Determinants of willingness to pay for multiple micronutrient powder.

\begin{tabular}{|c|c|c|c|c|c|}
\hline Variables & $\mathbf{N}$ & $\operatorname{COR}(95 \% \mathrm{Cl})$ & P-value & AOR $(95 \% \mathrm{Cl})$ & P-value \\
\hline \multicolumn{6}{|c|}{ Mother's age(years) } \\
\hline $15-24$ & 143 & 1 & & 1 & \\
\hline $25-34$ & 146 & $0.7(0.4-1.2)$ & 0.2 & $0.6(0.4-1.1)$ & 0.1 \\
\hline $35-49$ & 21 & $4.5(1.6-12.3)$ & 0.03 & $4.9(1.7-14.2)$ & $0.004 *$ \\
\hline \multicolumn{6}{|c|}{ Father's education } \\
\hline $\begin{array}{l}\text { No formal } \\
\text { education }\end{array}$ & 33 & 1 & & 1 & \\
\hline Primary & 241 & $1.8(0.8-4.2$ & 0.2 & $3.1(1.2-7.9)$ & $0.02 *$ \\
\hline Secondary & 36 & $1.2(0.4-3.5)$ & 0.7 & $2.1(0.6-6.9)$ & 0.2 \\
\hline \multicolumn{6}{|c|}{ Mother education } \\
\hline $\begin{array}{l}\text { No formal } \\
\text { education }\end{array}$ & 54 & 1 & & & \\
\hline Primary & 195 & $0.9(0.5-1.6)$ & 0.7 & & \\
\hline Secondary & 61 & $0.5(0.2-1.2)$ & 0.1 & & \\
\hline \multicolumn{6}{|c|}{ Livestock keeping } \\
\hline Yes & 207 & 1 & & 1 & \\
\hline No & 103 & $2.6(1.5-4.4)$ & 0 & $2.5(1.4-4.5)$ & $0.00 *$ \\
\hline \multicolumn{6}{|l|}{ Source of food } \\
\hline $\begin{array}{l}\text { Own } \\
\text { production }\end{array}$ & 85 & 1 & & & \\
\hline Buying & 225 & $0.7(0.46-1.29)$ & 0.3 & & \\
\hline \multicolumn{6}{|l|}{ Occupation } \\
\hline Employed & 31 & 1 & & & \\
\hline Farmers & 175 & $1.2(0.5-2.7)$ & 0.6 & & \\
\hline Pastoralist & 52 & $2.4(0.9-6.3)$ & 0.9 & & \\
\hline Casual labour & 43 & $0.9(0.3-2.6)$ & 0.8 & & \\
\hline Business & 9 & $1.2(0.25-5.9)$ & 0.5 & & \\
\hline \multicolumn{6}{|l|}{ Income (\$) } \\
\hline$>1.14$ & 45 & 1 & & 1 & \\
\hline$<1.14$ & 265 & $2.0(1.0-4.30)$ & 0.05 & $2.0(0.9-4.5)$ & 0.08 \\
\hline
\end{tabular}

what should be eaten, a position that allows them to significantly influence household expenditures on food and health [20]. Women have a higher preference than men to spend a larger share of the household budget on food and health which potentiates positive nutrition and health outcomes for household members, particularly their children [20]. In the current study, the mothers' WTP reflects the perceived health benefit which their children attained during the supplementation period.

In this study, results indicate that demographic and socioeconomic characteristics have a positive influence on parents' WTP for MNPs. Older mothers above 35 years and fathers with primary education demonstrated significant interest in purchasing MNP sachets for their children's health. These results are similar with other studies $[17,18,21]$. Parents with high education can understand the importance of nutrition counseling as the results they are easy to make a decision on purchasing MNPs and allocate money for nutritious products like micronutrient powder. Results from this study mirror with previous findings that mothers age was determinant factor of willing to pay for products $[17,22]$. In this study, it was found that not keeping 
animals was positively associated with WTP. It appears that nonanimal rearing families believe that their children's diets will lack the nutrients accessed from animal products (i.e., eggs, milk, and meat), hence increasing their WTP for MNPs. This was similar to a study in Iran where socioeconomic factors positively influenced WTP on an organic micronutrient product [23].

The child's age may influence mothers' WTP, with $63.5 \%$ of mothers with children below 2 years showing WTP for MNPs although statistically there is no significant difference from those who did not show WTP. Mothers with young children in the transition period from exclusive breastfeeding to CFs potentially have more demand to use nutritional products for child's health. However, the study did not show a significant association between child age and WTP. A study done in Ethiopia found that parents with children below 2 years were WTP for lipid-based nutrient supplements than parents with older children [24]. Family income was positively associated with WTP for MNPs in univariate analysis, but when combined with other factors in multivariate analysis, shows a weak association. Willingness to pay for nutritional products is beyond the financial ability of the parents, it can be influenced by many other factors. National health policy states that "children under five should receive health services free" but this does not apply when it comes to the provision of MNPs. Non-governmental organizations are dealing with distributing micronutrients through the dealers who sell them, as the services may be less than optimal in government hospitals where capacities focus on meeting basic health services for the majority of Tanzanian children. The limitation of this study is that, the assessment of WTP was performed once. The result can be further validated by assessing seasonally, twice per year as the purchasing power varies.

\section{Conclusion}

The socio-economic and demographic factors were found to contribute to WTP for MNPs. The findings help to understand market implications of nutritional products by investigating potential consumer factors on WTP for MNPs for sustainable marketing and distribution considerations. The factors found to

\section{References}

1 WHO (2011) Guideline: use of multiple micronutrient powders for home fortification of foods consumed by infants and children 6-23 months of age.

2 WHO (2001) Iron deficiency anaemia: assessment, prevention and control: a guide for programme managers.

3 Bondi SA, Lieuw K (2009) Excessive Cow's Milk Consumption and Iron Deficiency in Toddlers Two Unusual Presentations and Review. ICAN: Infant, Child \& Adolescent Nutrition 1: 133-139.

4 NBS and MACRO (2015) Tanzania Demographic and Health Survey. Preliminary findings. DHS. Dar es Salaam: National Bureau of Statistics, Dar es Salaam, Tanzania \& Macro.

5 Bhutta ZA, Salam RA, Das JK (2013) Meeting the challenges of micronutrient malnutrition in the developing world. British Medical Bulletin 106: 7-17. have significant associations with WTP were age, education, nonlivestock keeper, and income. Information on WTP can be useful for designers and planners in assessing the economic viability of projects, setting consumer cost parameters, evaluating policy alternatives, assessing financial sustainability, and designing socially equitable subsidies. It also provides useful information for developing marketing strategies for MNPs and assisting in the formulation of policies and education programs to ensure that families make the best possible choices for the health of their children. Based on the findings, it is possible to inform the national health policies to include nutritional supplementation considerations, such as the provision of MNPs to children, as a vector to enhancing future health and catalyzing social capital for the national.

\section{Key points}

- The majority (66\%) of families in our study were willing to pay for multiple micronutrient powders at a given price of 150 TZS (USD 0.068.

- Socioeconomic and demographic characteristics have a positive influence on parents' WTP for MNPs.

\section{Acknowledgements}

Special thanks to Gabriel Malima for editing the manuscript.

\section{Funding}

This study was funded by the Government of Tanzania through the Commission for Science and Technology (COSTECH).

\section{Competing Interests}

The authors declare that they have no competing interests.

\section{Ethical Statement}

Ethical clearance was obtained from the Ethics Committee of the National Institute of Medical Research (NIMR) Tanzania. Permission to undertake the study in Arusha district was obtained from the regional and district health departments.

6 Salam RA, MacPhail C, Das JK, Bhutta ZA (2013) Effectiveness of micronutrient powders (MNP) in women and children. BMC Public Health 13 (Suppl 3): S22.

7 HF-TAG U, WFP (2012) Programmatic guidance brief on use of micronutrient powders (mnp) for home fortification. Home Fortification Technical Advisory Group HF-TAG.

8 Adu-Afarwuah S, Lartey A, Brown KH, Zlotkin S, Briend A, et al. (2008) Home fortification of complementary foods with micronutrient supplements is well accepted and has positive effects on infant iron status in Ghana. Am J Clin Nutr 87: 929-938.

9 Ahmed F, Khan MR, Akhtaruzzaman M, Karim R, Marks GC, et al. (2005) Efficacy of twice-weekly multiple micronutrient supplementation for improving the hemoglobin and micronutrient status of anemic adolescent schoolgirls in Bangladesh. Am J Clin Nutr 82: 829-835.

10 Christofides A, Asante KP, Schauer C, Sharieff W, Owusu-Agyei S, et al. (2006) Multi-micronutrient Sprinkles including a low dose of 
iron provided as microencapsulated ferrous fumarate improves hematologic indices in anaemic children: a randomized clinical trial. Matern Child Nutr 2:169-180.

11 De-Regil LM, Suchdev PS, Vist GE, Walleser S, Peña-Rosas JP (2013) Home fortification of foods with multiple micronutrient powders for health and nutrition in children under two years of age (Review). Evidence-Based Child Health: A Cochrane Review Journal 8: 112-201.

12 Hyder SZ, Haseen F, Rahman M, Tondeur MC, Zlotkin SH (2007) Effect of daily versus once-weekly home fortification with micronutrient Sprinkles on hemoglobin and iron status among young children in rural Bangladesh. Food and Nutrition Bulletin 28:156-164.

13 Ip H, Hyder S, Haseen F, Rahman M, Zlotkin S (2009) Improved adherence and anaemia cure rates with flexible administration of micronutrient Sprinkles: a new public health approach to anaemia control. Eur J Clin Nutr 63:165.

14 Burger SE and Pierre-Louis JN (2002) How to assess iron deficiency anemia and use the HemoCue. New York: Hellen Keller International.

15 Munene CN (2005) Analysis of consumer attitudes and their willingness to pay for functional foods.

16 Alphonce R and Alfnes F (2012) Consumer willingness to pay for food safety in Tanzania: an incentive-aligned conjoint analysis. Int J Consum Stud 36: 394-400.

17 Aizuddin AN, Sulong S, Aljunid SM (2012) Factors influencing willingness to pay for healthcare. BMC Public Health 12: A37.
18 Chowdhury S, Meenakshi J, Tomlins KI, Owori C (2011) Are consumers in developing countries willing to pay more for micronutrient-dense bio fortified foods? Evidence from a field experiment in Uganda. American Journal of Agricultural Economics 93: 83-97.

19 Adams KP, Vosti SA, Lybbert TJ, Ayifah E (2011) Integrating Economic Analysis with a Randomized Controlled Trial: Willingness-to-Pay for a New Maternal Nutrient Supplement. in Agricultural and Applied Economics Association, 2011 Annual Meeting, Pittsburgh, Pennsylvania.

20 Allendorf K (2007) Do women's land rights promote empowerment and child health in Nepal? World Development 35:1975-1988.

21 Nguyen PH, Hoang MV, Hajeebhoy N, Tran LM, Le CH, et al. (2015) Maternal willingness to pay for infant and young child nutrition counseling services in Vietnam. Glob Health Action 8: 28001.

22 Xia W, Zeng Y (2008) Consumer's willingness to pay for organic food in the perspective of meta-analysis. Paper Presented in the International Conference on Applied Economics.

23 Haghjou M, Hayati B, Pishbahar E, Mohammadrezaei R, Dashti G (2013) Factors affecting consumers' potential willingness to pay for organic food products in Iran: Case study of Tabriz. Journal of Agricultural Science and Technology 15:191-202.

24 Segrè J, Winnard K, Abrha TH, Abebe Y, Shilane D, et al. (2015) Willingness to pay for lipid-based nutrient supplements for young children in four urban sites of Ethiopia. Matern Child Nutr 11:16-30. 